Diagnostic delay:

Medical mystery

program puts a hold

on new applications

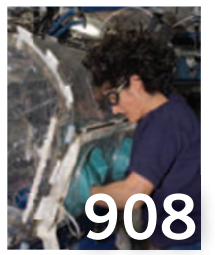

The final frontier:

Space biomedicine

braces for a post-

Shuttle era

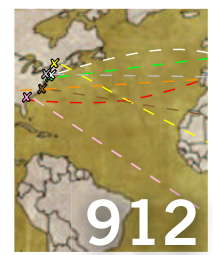

Jet-set science:

The benefits of

maintaining labs on

multiple continents

\title{
Exploratory grant scheme abandoned after failing to meet its goals
}

Last year, tissue bioengineer Jeffrey Borenstein decided to pursue a long-incubating idea. He wanted to create an artificial lung that that could work for months on end without recipients having to take blood-thinning drugs like they do with existing models. None of his existing grants included funding to cover this project. And with little preliminary data to show for his fledgling idea, he figured he didn't stand much of a chance at securing an R01 grant, the most widely used funding vehicle at the US National Institutes of Health (NIH) for specific research projects.

So Borenstein, director of the biomedical engineering center at the Charles Stark Draper Laboratory in Cambridge, Massachusetts, applied for an R21 grant, which provides transitionary funding for researchers with little initial data to explore high-risk, highreward projects. The grant only provides up to $\$ 275,000$ over two years, but the idea is that investigators are then in a better position to secure much more lucrative R01 funding.

The US National Heart, Lung, and Blood Institute (NHLBI) funded Borenstein's grant in November to the tune of $\$ 260,000$. On the basis of previous funding, he reported in April how microfluidic technologies enable high levels of gas exchange in a densely packed structure-a far more efficient method than the current bulky mechanical ventilators (Biomed. Microdevices 13, 315-23, 2011). With the R21 grant, he is now developing strategies for lining the microscopic vessels with endothelial cells to reduce the common problem of blood clots on artificial surfaces.

"Our goal is to use this new technology platform for a host of artificial organ applications," Borenstein says.

Had he waited much longer to apply, however, Borenstein might never have received the funding, because on 12 July the NHLBI announced that the institute would no longer accept unsolicited R21 grant applications after October because the funding was not serving its intended purpose.

The R1 grants are meant "to get you to the point where you can apply for an R01," explains Susan Shurin, acting director of the NHLBI, headquartered in Bethesda, Maryland. But the funded ideas "weren't transitioning into independent, investigator-controlled grants," she says.

Many young investigators view R21s as stepping stones to R01s. But at a 15 June NHLBI advisory council meeting, the institute's acting deputy director Carl Roth presented data showing that early-career researchers obtain $\mathrm{R} 21 \mathrm{~s}$ at half the success rate of their more senior counterparts, whereas new and experienced investigators receive R01s at a similar rate.

"The R21s are interesting in that a lot of people thought, 'Oh boy, these are easy pickings," says Howard Garrison, deputy executive director for policy at the Federation of American Societies for Experimental Biology in Washington, DC. Their popularity stems largely from their "reputation for being easier than R01s," he notes, rather than the proof-of-principle projects they were meant to finance.

Although the NHLBI will stop funding unsolicited exploratory grants, according to Shurin the institute will continue to occasionally put out calls for R21 applications for specific research projects defined by the institute-but only from established researchers with at least two R01s under their belts.

\section{Exploring all options}

It's not the first time that agency officials have abandoned a funding scheme. In the late 1990s, the NIH discontinued the R29 grant program-a low-budget alternative to $\mathrm{R} 01 \mathrm{~s}$ designed to give young investigators easier access to the funding system-after a working group found that R29 recipients were no more likely to secure R01s than those new researchers who never held a bridge grant.

"To bring new investigators in on the cheap was a bad idea then, and it's a bad idea now," says Marvin Cassman, former director of the US National Institute of General Medical Sciences who co-chaired the working group that led to the R29 grant's demise. "Unless you give people the amount of time and amount of money they need, there's no reason you should expect them as a group to be successful."

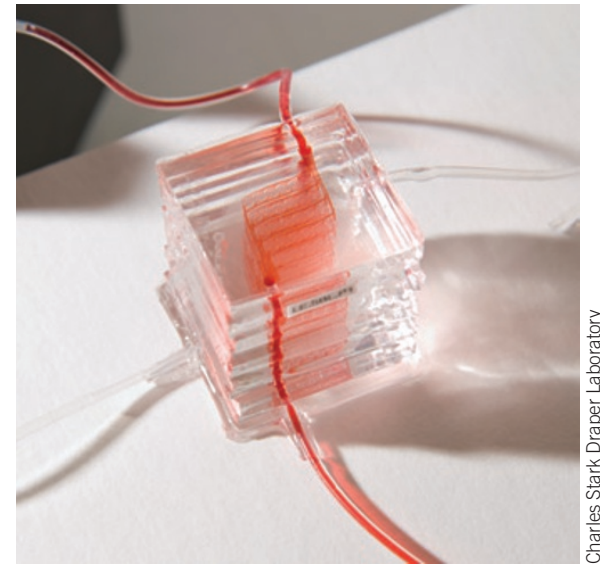

Think lung and hard: The R21-funded "lung".

The NHLBI may be the first institute to dump investigator-initiated R21s, but the writing is already on the wall that other institutes may follow suit. In May of last year, the US National Institute of Neurological Disorders and Stroke issued a notice encouraging new researchers to apply for R01s, not R21s, after finding similar discrepancies in success rates as at the NHLBI.

Across the NIH, administrators are rethinking all of their grant mechanisms, including R21s, according the agency's chief of extramural research Sally Rockey. With the NIH's flattened budget, if a grant program isn't meeting its goals, the cash should be diverted into successful programs, she says. "It just really depends on the institute and how they're managing their portfolios."

Borenstein emphasizes the importance of diverse funding mechanisms to "advance a lot of these ideas from labs like ours towards the clinic," but he's not mourning the loss of the R21 program. He remains confident that, given enough time to generate preliminary data, he would have secured funding for his project anyway. Although it may have taken him longer to land a grant, "I just would have applied for an R01," he says, echoing what the NHLBI is advising its grant applicants to do. "We would find one way or another to try to push this forward."

Hannah Waters 